\author{
Robert Czarnota*, Damian Janiga*, \\ Jerzy Stopa*, Paweł Wojnarowski*
}

\title{
PREDICTING RELATIVE PERMEABILITY FROM EXPERIMENTAL CAPILLARY PRESSURE POROUS PLATE TEST FOR TWO PHASE FLOW**
}

\section{INTRODUCTION}

Routine core analysis and special core analysis in laboratory conditions are worldwide performed as a part of hydrocarbon migration investigation. Porosity and absolute permeability data are useful during developing a static model of geological structure rich in crude oil. In spite of pressure gradient, relative permeability and capillary pressure functions are necessary for dynamic modeling to characterize the possible hydrocarbon migration process. It is generally agreed that the inter-connected pore spaces, channels and fractures of reservoir rocks were originally filled with water, after which oil moved into the reservoir, displacing some of the water, and reducing the water to some residual saturation. These conditions are restored for the prediction capillary pressure and relative permeability.

Capillary pressure plays an important role in the migration and displacement of the two-phase, water-oil, flow system. The capillary pressure depends on the curvature of the interface separating the two immiscible fluids. Surface between two immiscible fluids has the tendency to shrink into the smallest possible area per unit volume [1].

* AGH University of Science and Technology, Faculty of Drilling, Oil and Gas, Krakow, Poland

** The research leading to these results has received funding from the Polish-Norwegian Research Programme operated by the National Centre for Research and Development under the Norwegian Financial Mechanism 2009-2014 in the frame of Project Contract No. Pol-Nor/235294/99/2014 
The displacement of one fluid by another in a porous medium is either aided or opposed by the surface forces. As a consequence, a porous medium is exposed to wetting fluid, while retaining a rock fragmentarily saturated with non-wetting fluid it is necessary to maintain the pressure of the non-wetting fluid at a value greater than that in the wetting fluid. The capillary pressure in a petroleum reservoir is the result of the connected effect of the surface and interfacial tensions of the rock and fluids, the pore radius and the wetting characteristics of the porous media.

Capillary pressure is defined as difference in fluid pressure between the non-wetting phase $\left(P_{n w}\right)$ and wetting phase $\left(P_{w}\right)$. Generally is given in terms of interfacial tension $(\sigma)$, contact angle $(\theta)$ and the radius of maximum pore throat $(r)[3,15,18]$ the mathematical expression of which is represented by the following form:

$$
P_{c}=P_{n w}-P_{w}=\frac{2 \cdot \sigma_{o-w} \cdot \cos (\theta)}{r}
$$

The minimum differential pressure is required to displace the wetting phase from the largest capillary pore because any capillary of smaller radius will demand a higher pressure. As the wetting phase is desaturated the second phenomenon of immiscible displacement process is faced with reaching of some finite minimum irreducible saturation.

In the petroleum engineering three different techniques of capillary pressure measurement are in use, these are: mercury-air injection, high-speed centrifuge and porous plate method. Although air/mercury injection technique is commonly applied [17, 19, 20], this method has several weak points. As mercury is injected under high pressure, sensitive pores can be damaged. Due to complete compressibility of air at high pressures, no irreducible water saturation is registered and pore volume is filled with mercury. During this experiment, reservoir fluids are not used [16]. High speed centrifuge technique entails saturation regimes and stress patterns that do not take place under reservoir conditions. If insufficient time is given to achieve capillary equilibrium, water saturation can be underestimated. The main drawback for porous plate technique is time necessitated to generate a full capillary pressure curve. Equilibrium saturation time is controlled by water flux volume flowed through the semi-permeable membrane. Exceptionally low permeability of ceramic disk slow down the drain of water from rock plug, therefore measurement for unconventional oil and gas bearing formations like tight sandstone, shale or coal can lasts even several months. Nonetheless, this technique assures the most solid results and guarantee a uniform saturation.

The absolute permeability is a property of the porous medium and is a measure of the capacity of the medium to transmit fluids. The relative permeability of each phase 
at a specific saturation is the ratio of the effective permeability of the phase to the absolute permeability [1]. When a wetting and a non-wetting phase flow together at the same time in a reservoir rock, each phase follows separate and distinct paths. The distribution of the two phases according to their wetting characteristics results in characteristic wetting and non-wetting phase relative permeabilities. Since the wetting phase occupies the smaller pore openings at relatively low saturations, and these pore openings do not contribute materially to flow, it follows that the presence of a small wetting phase saturation will affect the non-wetting. Therefore, water-oil relative permeability is a function of the wetting characteristics of the formation at which a given effective permeability exists. Typical relative permeability curves for water-oil system are presented in Figure 1.

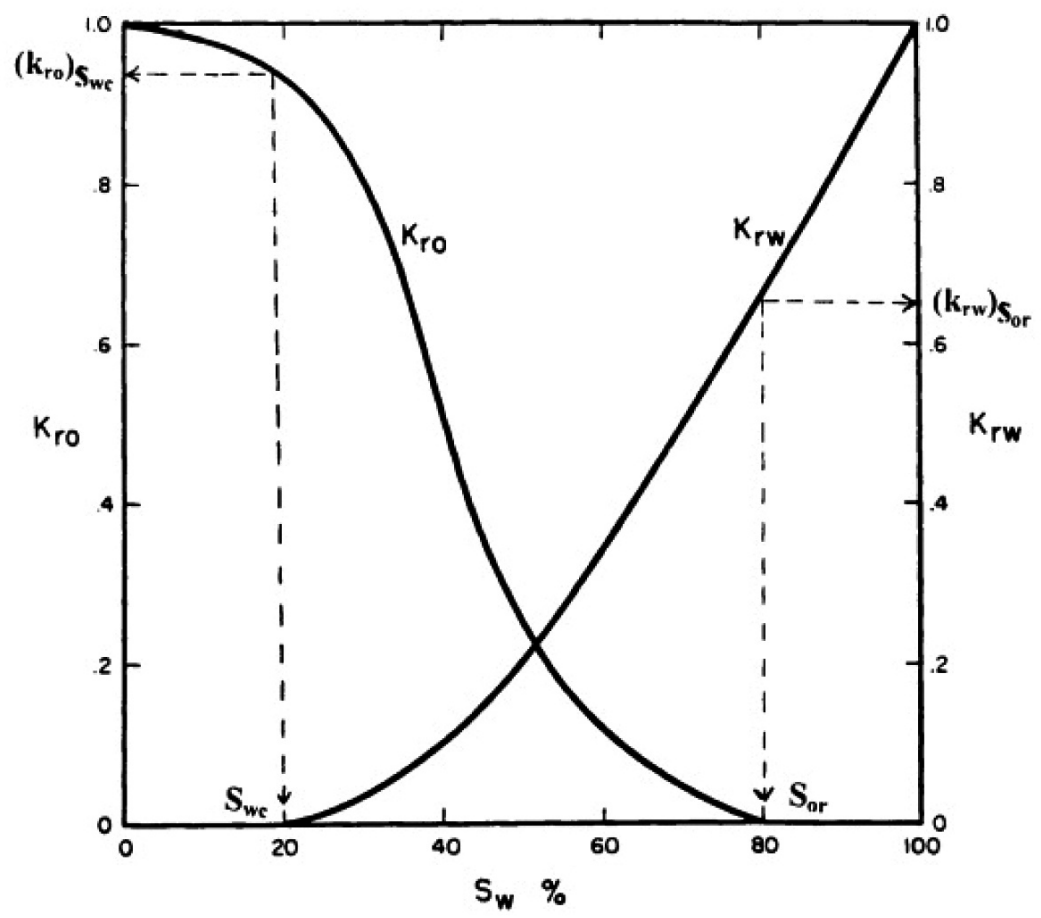

Fig. 1. Water-oil relative permeability curves (after [1])

The commonly used techniques for measurement relative permeability can be sub-divided as direct laboratory methods and indirect predictive methods. Direct laboratory data from steady-state or unsteady-state techniques [2, 6, 9-11, 13] are not always available [8]. Through years some indirect predictive models were developed and are used widely. 
Purcell [14] proposed an equation to calculate relative permeability from capillary pressure data. Burdine [5] extended Purcell's model by taking in account a tortuosity factor as a function of wetting phase saturation in the computation of relative permeability from the capillary pressure data. Corey [7] noted that oil-gas capillary pressure curves can be approximated by using a simple mathematical linear relation. Brook-Corey [4] model included a pore size distribution index $\lambda$ which is calculated directly from a best-fit regression line drawn through of capillary pressure and water saturation data in log-log scale. In this study equations (2)-(5) were used to calculate relative permeability curves from directly registered capillary pressure data for dolomite samples.

$$
S_{e}=\frac{S_{w}-S_{w r}}{1-S_{w r}}
$$

where:

$S_{e}-$ effective saturation,

$S_{w}$ - water saturation,

$S_{w r}-$ irreducible water saturation.

$$
\log \left(P_{c}\right)=\log \left(P_{e}\right)-\frac{1}{\lambda} S_{e}
$$

where:

$P_{c}$ - capillary pressure,

$P_{e}$ - entry capillary pressure,

$\lambda$ - pore size distribution index.

$$
k_{r w}=\left(S_{e}\right)^{\frac{2+3 \lambda}{\lambda}}
$$

where $k_{r w}$ - water relative permeability.

$$
k_{r o}=\left[1-S_{e}\right]^{2} \cdot\left[1-\left(S_{e}\right)^{\frac{2+\lambda}{\lambda}}\right]
$$

where $k_{r o}$ - oil relative permeability. 


\section{EXPERIMENT}

\subsection{Materials}

Porosity and pore volume were calculated from determined values of bulk volume, mass of dry and fully saturated with brine core plugs. Gas phase permeability varies with mean pressure, because of the occurrence of the slippage phenomenon [12]. Hence, by plotting gas permeability against the reciprocal of the mean pressure, the values of the absolute permeability are determined from the intercepts of the $K_{g}$ vs. $1 / P_{m}$ straight line where $P_{m}$ approaches infinity. Absolute permeabilities of dried rock plugs were measured using nitrogen at $23^{\circ} \mathrm{C}$. The petrophysical properties of rock plugs are included in Table 1.

Table 1

Characteristic of rock sample

\begin{tabular}{|c|c|c|c|c|c|c|}
\hline $\begin{array}{c}\text { Core } \\
\text { ID }\end{array}$ & $\begin{array}{c}\text { Length } \\
{[\mathrm{cm}]}\end{array}$ & $\begin{array}{c}\text { Diameter } \\
{[\mathrm{cm}]}\end{array}$ & $\begin{array}{c}\text { Effective } \\
\text { porosity } \\
{[\%]}\end{array}$ & $\begin{array}{c}\text { Pore } \\
\text { volume } \\
{\left[\mathrm{cm}^{3}\right]}\end{array}$ & $\begin{array}{c}\text { Permeability } \\
{\left[\mathrm{m}^{2}\right]}\end{array}$ & $\begin{array}{c}\text { Density } \\
{\left[\mathrm{kg} / \mathrm{m}^{3}\right]}\end{array}$ \\
\hline $\mathrm{A}$ & 9.48 & 3.79 & 25.15 & 16.31 & $15.14 \cdot 10^{-15}$ & 2320 \\
\hline $\mathrm{B}$ & 7.52 & 3.79 & 21.62 & 20.89 & $21.06 \cdot 10^{-15}$ & 2106 \\
\hline $\mathrm{C}$ & 7.74 & 3.81 & 15.58 & 18.48 & $7.96 \cdot 10^{-15}$ & 2142 \\
\hline
\end{tabular}

\subsection{Apparatus}

The experimental facility constitutes: two accumulators, three injection pumps used for controlling overburden, inlet and outlet pressures, vertically installed coreholder and differential pressure transducer. All moveable piston type transfer cylinders are connected to the syringe pumps for storing and flowing the test fluids. Coreholder and containers are made of highly corrosion resistant metal alloy - Hastelloy C-276. Characteristics of porous plate is given in Table 2 and Reservoir Conditions Capillary Pressure (RCCP) apparatus is shown in Figure 2. The unit can be operated at pressures up to $70 \mathrm{MPa}$ and temperatures up to $150^{\circ} \mathrm{C}$.

Table 2

Ceramic disk characteristics

\begin{tabular}{|c|c|c|c|c|}
\hline $\begin{array}{c}\text { Diameter } \\
{[\mathrm{cm}]}\end{array}$ & $\begin{array}{c}\text { Thickness } \\
{[\mathrm{cm}]}\end{array}$ & $\begin{array}{c}\text { Threshold } \\
\text { pressure } \\
{[\mathrm{bar}]}\end{array}$ & $\begin{array}{c}\text { Effective } \\
\text { porosity } \\
{[\%]}\end{array}$ & $\begin{array}{c}\text { Permeability } \\
{\left[\mathrm{m}^{2}\right]}\end{array}$ \\
\hline 3.81 & 0.725 & 15 & 0.3 & $0.005 \cdot 10^{-15}$ \\
\hline
\end{tabular}




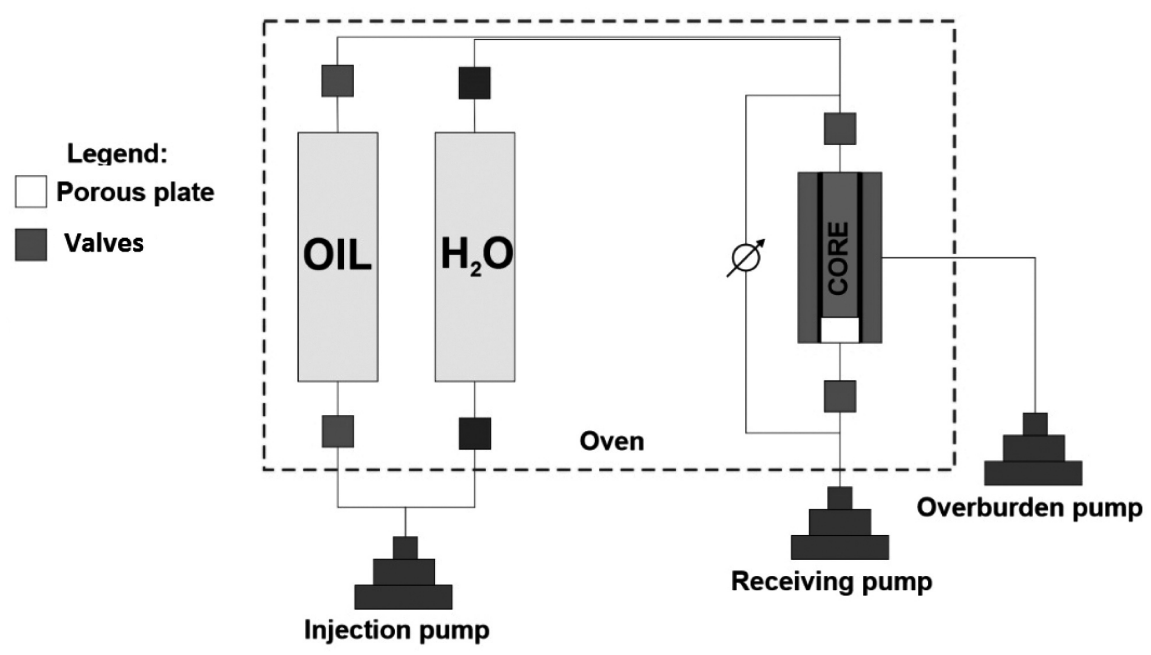

Fig. 2. Diagrammatic sketch of RCCP equipment

\subsection{Procedure}

A quasi-static method to register capillary pressure was chosen. The water-wet disk was put on the downstream end, then a layer of tissue paper was placed between the core sample end face. After that core sample was placed vertically in the core holder. In the first step, core sample was saturated with $3 \%$ brine aged in the core holder with porous plate at reservoir conditions, corresponding to a confining pressure of $3000 \mathrm{psi}$, pore pressure of $2000 \mathrm{psi}$ and temperature equal $50^{\circ} \mathrm{C}$ for 1 week. For the oil injection pump inlet pressure was maintained constant, and the out let pressure was decreased to initiate the primary drainage process. When the pressure difference was provided across the rock sample water started to flow out of the core through the water-wet membrane. In this way, only brine passed through porous plate because the applied pressure difference was lower than the threshold pressure of the disk. As the water saturation decreased, the capillary pressure increased. After a long period of time, the capillary pressure was equal to the applied pressure difference and the change of water production volume became zero. As result the pressure difference and saturation in the rock sample was constant. At this time the system reached capillary equilibrium. Then saturation in the rock sample was calculated from the volume change of the receiving pump and capillary pressure was equal to the applied pressure difference. This constitutes a point on the capillary pressure curve. A higher pressure difference was applied to move on to the next stage. This procedure was repeated until the irreducible water saturation was reached and full capillary pressure curve was registered. In the last step relative permeability curves were generated using Brook-Corey model. 


\section{RESULTS}

Capillary pressure test for dolomite rock plugs with porous plate technique under reservoir conditions was performed. In Figure 3 directly registered capillary pressure curves are shown and in Table 3 measured capillary pressure values at corresponding water saturation are given. In Figures 4-6 water and oil relative permeability curves generated from capillary pressure data are presented. Relative permeability values calculated using Brook-Corey model are in Tables 3-5.

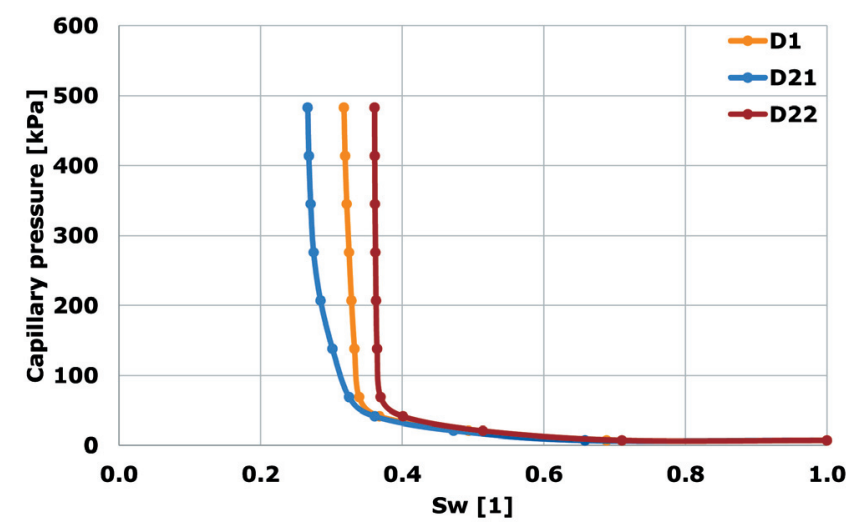

Fig. 3. Directly registered capillary pressure curves for dolomite rock plugs

Table 3

Capillary pressure values at water saturation

\begin{tabular}{|c|c|c|c|}
\hline \multirow{2}{*}{$\begin{array}{c}\text { Capillary pressure } \\
{[\mathrm{kPa}]}\end{array}$} & \multicolumn{3}{|c|}{ Water saturation [1] } \\
\cline { 2 - 4 } & Sample A & Sample B & Sample C \\
\hline 7 & 1.0000 & 1.0000 & 1.0000 \\
\hline 7 & 0.6887 & 0.6583 & 0.7104 \\
\hline 21 & 0.4938 & 0.4724 & 0.5139 \\
\hline 41 & 0.3678 & 0.3612 & 0.4012 \\
\hline 69 & 0.3392 & 0.3251 & 0.3696 \\
\hline 138 & 0.3326 & 0.3015 & 0.3645 \\
\hline 207 & 0.3283 & 0.2846 & 0.3630 \\
\hline 276 & 0.3249 & 0.2748 & 0.3623 \\
\hline 345 & 0.3217 & 0.2707 & 0.3616 \\
\hline 414 & 0.3193 & 0.2681 & 0.3612 \\
\hline 483 & 0.3177 & 0.2665 & 0.3609 \\
\hline
\end{tabular}




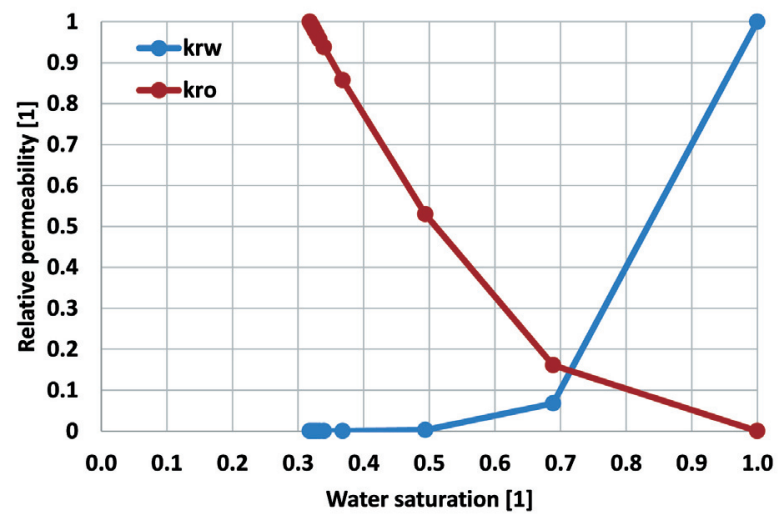

Fig. 4. Relative permeability curves for A dolomite sample generated from capillary pressure data

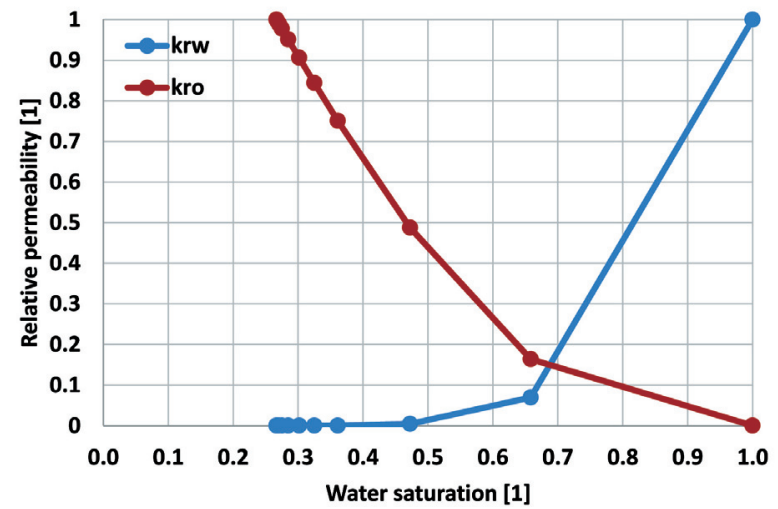

Fig. 5. Relative permeability curves for B dolomite sample generated from capillary pressure data

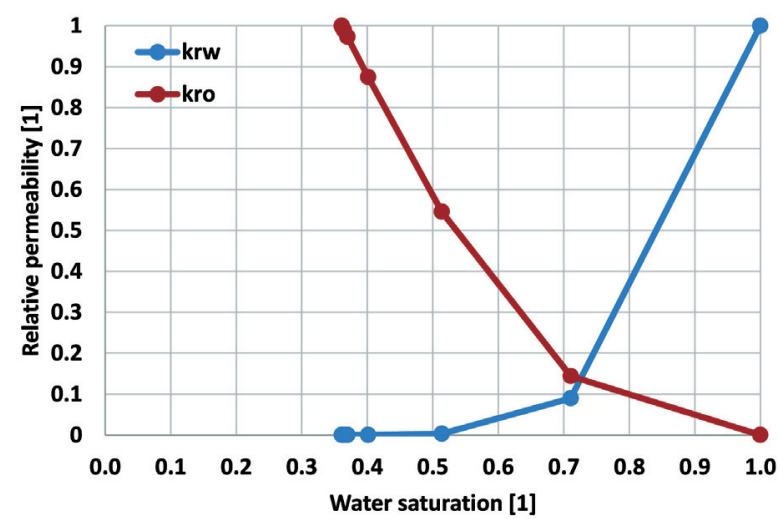

Fig. 6. Relative permeability curves for $\mathrm{C}$ dolomite sample generated from capillary pressure data 
Table 4

Relative permeability values for A dolomite sample

\begin{tabular}{|c|c|c|}
\hline Water saturation [1] & Krw [1] & Kro [1] \\
\hline 1.0000 & 1 & 0.160671238 \\
\hline 0.6887 & 0.067413663 & 0.529885277 \\
\hline 0.4938 & 0.002487263 & 0.857055957 \\
\hline 0.3678 & $9.51449 \mathrm{E}-06$ & 0.93791166 \\
\hline 0.3392 & $2.22605 \mathrm{E}-07$ & 0.956740903 \\
\hline 0.3326 & $4.42582 \mathrm{E}-08$ & 0.969150055 \\
\hline 0.3283 & $9.80301 \mathrm{E}-09$ & 0.979012126 \\
\hline 0.3249 & $1.76585 \mathrm{E}-09$ & 0.98831835 \\
\hline 0.3217 & $1.30816 \mathrm{E}-10$ & 0.995384928 \\
\hline 0.3193 & $2.12853 \mathrm{E}-12$ & 1 \\
\hline 0.3177 & 0 & \\
\hline
\end{tabular}

Table 5

Relative permeability values for B dolomite sample

\begin{tabular}{|c|c|c|}
\hline Water saturation [1] & Krw [1] & Kro [1] \\
\hline 1.0000 & 1 & 0.164086837 \\
\hline 0.6583 & 0.069551344 & 0.487787052 \\
\hline 0.4724 & 0.004509145 & 0.75093289 \\
\hline 0.3612 & 0.000165893 & 0.84387718 \\
\hline 0.3251 & $2.14852 \mathrm{E}-05$ & 0.905908968 \\
\hline 0.3015 & $2.40798 \mathrm{E}-06$ & 0.951045945 \\
\hline 0.2846 & $1.45832 \mathrm{E}-07$ & 0.977476242 \\
\hline 0.2748 & $5.28774 \mathrm{E}-09$ & 0.988583939 \\
\hline 0.2707 & $2.91887 \mathrm{E}-10$ & 0.995706123 \\
\hline 0.2681 & $4.54339 \mathrm{E}-12$ & 1 \\
\hline 0.2665 & 0 & \\
\hline
\end{tabular}


Table 6

Relative permeability values for $\mathrm{C}$ dolomite sample

\begin{tabular}{|c|c|c|}
\hline Water saturation [1] & Krw [1] & Kro [1] \\
\hline 1.0000 & 1 & 0.143859 \\
\hline 0.7104 & 0.089509 & 0.545374 \\
\hline 0.5139 & 0.003287 & 0.874468 \\
\hline 0.4012 & $1.58 \mathrm{E}-05$ & 0.972976 \\
\hline 0.3696 & $3.35 \mathrm{E}-08$ & 0.988925 \\
\hline 0.3645 & $9.44 \mathrm{E}-10$ & 0.993427 \\
\hline 0.3630 & $1.17 \mathrm{E}-10$ & 0.995833 \\
\hline 0.3623 & $1.89 \mathrm{E}-11$ & 0.997966 \\
\hline 0.3616 & $1.07 \mathrm{E}-12$ & 0.999237 \\
\hline 0.3612 & $2.14 \mathrm{E}-14$ & 1 \\
\hline 0.3609 & 0 & \\
\hline
\end{tabular}

\section{CONCLUSION}

The capillary pressure data were registered under restored reservoir conditions and reproduced the drainage behavior of hydrocarbon migration. In this study state-of-the art equipment allowed to measure a change in expelled volume with the precision of $0.0001 \mathrm{cc}$ for the 10 capillary pressure steps. Maximum value of capillary pressure was equal $483 \mathrm{kPa}$ for the average $22.27 \%$ irreducible water saturation. Application of porous plate method provides sufficient stabilization time, allowing to achieve uniform saturation distribution. The Brook-Corey model was applied to generate the full water-oil relative permeability curves.

Capillary pressure prevents non-wetting fluid from flowing into the porous medium in presence of wetting fluid. Hence, reservoir rocks associated with an excessive capillary pressure prevent the buoyant fluid migration. The adsorption of hydrocarbon molecules on the surface of the dolomite can reduce the capillary resistance for oil migration. A benefit from using a quasi-static porous plate method for measurement of capillary pressure is the ability of registering at the same time with high accuracy the drainage relative permeability and capillary pressure curves. In this way more information can be obtained from the same rock sample what improve the accuracy of the multiphase flow description. 


\section{REFERENCES}

[1] Ahmed T.: Reservoir engineering handbook. 4th ed. Gulf Professional Publishing, 2010.

[2] Alizadeh A.H., Piri M.: The effect of saturation history on three-phase relative permeability: An experimental study. Water Resources Research, 50 (2), 2014, pp. 1636-1664.

[3] Boulin P.F., Bretonnier P., Vassil V., Samouillet A., Fleury M., Lombard J.M.: Sealing efficiency of caprocks: Experimental investigation of entry pressure measurement methods. Marine and Petroleum Geology, 48, 2013, pp. 20-30.

[4] Brooks R.H., Corey A.T.: Properties of porous media affecting fluid flow. Journal of the Irrigation and Drainage Division, 92(2), 1966, pp. 61-90.

[5] Burdine N.: Relative permeability calculations from pore size distribution data. Journal of Petroleum Technology, 5(03), 1953, pp. 71-78.

[6] Chen X., Kianinejad A., DiCarlo D.A.: An experimental study of $\mathrm{CO}_{2}$-brine relative permeability in sandstone. in: SPE improved oil recovery symposium. Society of Petroleum Engineers, April 2014.

[7] Corey A.T.: The interrelation between gas and oil relative permeabilities. Producers Monthly, 19(1), 1954, pp. 38-41.

[8] Honarpour M.M., Koederitz L., Harvey A.H.: Relative Permeability of Petroleum Reservoirs. CRC Press, Boca Raton, Fla, 1986.

[9] Kianinejad A., Aminzadeh B., Chen X., DiCarlo D.A.: Three-phase relative permeabilities as a function of flow history. in: SPE Improved Oil Recovery Symposium. Society of Petroleum Engineers, April 2014.

[10] Kianinejad A., Chen X., DiCarlo D.A.: The effect of saturation path on three-phase relative permeability. Water Resources Research, 51(11), 2015, pp. 9141-9164.

[11] Kianinejad A., Chen X., DiCarlo D.A.: Three-Phase Relative Permeability in Consolidated Media. in: SPE Annual Technical Conference and Exhibition. Society of Petroleum Engineers, September 2015.

[12] Klinkenberg L.J.: The permeability of porous media to liquids and gases. in: Drilling and production practice. American Petroleum Institute, January 1941.

[13] Krevor S., Pini R., Zuo L., Benson S.M.: Relative permeability and trapping of $\mathrm{CO}_{2}$ and water in sandstone rocks at reservoir conditions. Water Resources Research, 48(2), 2012.

[14] Purcell W.R.: Capillary pressures-their measurement using mercury and the calculation of permeability therefrom. Journal of Petroleum Technology, 1(02), 1949, pp. 39-48. 
[15] Rashid F., Glover P.W.J., Lorinczi P., Hussein D., Collier R., Lawrence J.: Permeability prediction in tight carbonate rocks using capillary pressure measurements. Marine and Petroleum Geology, 68, 2015, pp. 536-550.

[16] Rezaee R., Saeedi A., Clennell B.: Tight gas sands permeability estimation from mercury injection capillary pressure and nuclear magnetic resonance data. Journal of Petroleum Science and Engineering, 88, 2012, pp. 92-99.

[17] Schmitt M., Fernandes C.P., da Cunha Neto J.A., Wolf F.G., dos Santos V.S.: Characterization of pore systems in seal rocks using nitrogen gas adsorption combined with mercury injection capillary pressure techniques. Marine and Petroleum Geology, 39(1), 2013, pp. 138-149

[18] Watts N.L.: Theoretical aspects of cap-rock and fault seals for single-and two-phase hydrocarbon columns. Marine and Petroleum Geology, 4(4), 1987, pp. 274-307.

[19] Wu F., Fan Q., Huang D., Ma L., Liang X., Sima L.: Predicting gas-water relative permeability using Nuclear Magnetic Resonance and Mercury Injection Capillary Pressure measurements. Journal of Natural Gas Science and Engineering, 32, 2016, pp. 35-47.

[20] Xi K., Cao Y., Haile B.G., Zhu R., Jahren J., Bjřrlykke K., Zhang X., Hellevang H.: How does the pore-throat size control the reservoir quality and oiliness of tight sandstones? The case of the Lower Cretaceous Quantou Formation in the southern Songliao Basin, China. Marine and Petroleum Geology, 76, 2016, pp. 1-15. 